\title{
A TRADUÇÃO DE "INVISIBLE MAN", DE RALPH ELLISON: O JOGO ENTRE RACIALIDADE E INTEGRACIONISMO
}

\author{
Debora Larissa Rempel*
}

Lauro Maia Amorim**

\begin{abstract}
Resumo: A relação entre materialidade tradutória e discurso constitui um dos enfoques no vínculo entre Estudos da Tradução e literatura afro-americana. Em "Invisible Man", do autor afro-americano Ralph Ellison, e em sua tradução, realizada por Márcia Serra, mostra-se propício analisar, nesse sentido, contextos que ativam a percepção de senso de comunidade e identidade racial. Neste artigo, enfocam-se, portanto, nuances de sentido em marcas linguísticas de adesão e racialidade, notando-se que tais aspectos aparecem de forma menos incisiva na tradução. Por outro lado, observou-se que o projeto integracionista presente no romance foi marcado em certa medida por uma reescrita com efeito de dicotomização racial. Assim, a tradução manifesta tanto a leitura não racializada inerente à formação discursiva brasileira quanto pressupostos sobre a visão do Outro afro-americano a respeito de relações raciais.
\end{abstract}

Palavras-chave: Estudos da Tradução. Literatura afro-americana. Ralph Ellison. Racialidade.

\footnotetext{
* Debora Larissa Rempel. Formada em Letras com Habilitação de Tradutor pela Universidade Estadual Paulista "Júlio de Mesquita Filho", Instituto de Biociências, Letras e Ciências Exatas. São José do Rio Preto, São Paulo. Brasil. E-mail: debora.rempel@terra.com.br

** Lauro Maia Amorim. Doutor em Translation Studies pela State University of New York at Binghamton, EUA. É Professor Assistente Doutor no Curso de Letras Bacharelado com Habilitação de Tradutor e no Programa de Pós-Graduação em Estudos Linguísticos (Linha de Pesquisa: Estudos da Tradução) na Universidade Estadual Paulista "Júlio de Mesquita Filho", Instituto de Biociências, Letras e Ciências Exatas, Departamento de Estudos Linguísticos e Literários. São José do Rio Preto, São Paulo. Brasil. Email: lauromar@ibilce.unesp.br
} 


\title{
THE TRANSLATION OF "INVISIBLE MAN", BY RALPH ELLISON: THE INTERPLAY OF RACE AND INTEGRATIONISM
}

\begin{abstract}
Relating the surface of a translated text to discourse is one of the focuses in the connection between Translation Studies and African-American literature. In this respect, "Invisible Man”, by Ralph Ellison, and its Brazilian translation, by Márcia Serra, present themselves as material for analyzing contexts which evoke a sense of community and racial identity. Therefore, this paper centers precisely upon nuances in meaning of the linguistic displays of bonding and race. It could be noticed that these aspects were less marked in the translation, whereas the integrationist project featured in the novel was to a certain extent rewritten in words that called forth a sense of racial dichotomy. Thus, the translation displays at once the non-racialized perspective peculiar to the Brazilian view of race and assumptions in regard to the perspective of the African-American Other on race relations.
\end{abstract}

Keywords: Translation Studies. African-American literature. Ralph Ellison. Blackness.

\section{Introdução}

O estudo de relações discursivas suscitadas pela tradução de aspectos concernentes à negritude na literatura afro-americana insere-se em um cenário de crescente aproximação entre os Estudos Culturais e os Estudos da Tradução. Tal panorama vem sendo construído a partir da busca por novas tendências de enfoque no campo da recepção literária, intuito refletido em propostas como o levantamento de traduções brasileiras para obras afro-americanas feito por Hattnher (1998) e o estudo do papel de escritoras afro-americanas no Brasil desenvolvido por Salgueiro (2006). Salgueiro, especificamente, assinala em sua abordagem o papel da tradução como mediadora de culturas, expressando, tal como Venuti (2002), a consciência de que a mesma envolve a reformulação de diferenças culturais e linguísticas. Conforme Venuti frisa, ainda, o ato de traduzir é perpassado por escolhas associadas à formação 
ideológica, embora as mesmas não necessariamente sejam feitas de forma consciente ou tenham aplicação previsível. Nesse sentido, a título de ilustração para a maneira como a formação identitária impacta a materialidade tradutória, pode-se citar um artigo de Amorim (2012) que contempla a análise, em um poema de Langston Hughes, do modo pelo qual opções de tradução potencializam, mediante seus efeitos de sentido, a harmonia ou dissonância entre o aspecto racial afro-americano e as expectativas de um leitor brasileiro sobre racialidade. Aqui acrescentamos, com o fim de circunscrever a perspectiva de "raça" tal qual concebida nesta discussão, que não a tomamos como enquadramento de um grupo em paradigmas supostamente delimitáveis por constituição genética, e sim como uma construção discursiva, sem com essa relativização, porém, negar sua problemática conflituosa.

Diante das reflexões apresentadas, o presente artigo ${ }^{1}$ tem como objetivo, portanto, destacar relações entre o discurso afrodescendente e a teia de significações na tradução (1990, Ed. Marco Zero, trad. Márcia Serra) de Invisible Man (1952), romance de Ralph Ellison.

\section{Invisible Man/Homem Invisível e seus contextos discursivos}

Invisible Man centra-se em um personagem anônimo que muda sua visão sobre raça ao longo da narrativa, de modo que ele, inicialmente arraigado em tradições do Sul dos EUA, começa a desconstruir sua concepção de necessário distanciamento entre grupos raciais quando convidado a ser orador de uma confraria inter-racial. Nessa organização, ele vivencia o engajamento de brancos e negros em diversas frentes, incluindo as questões socioeconômicas da comunidade do Harlem. Essa cooperação em torno à comunidade afro-americana renova suas perspectivas sobre as relações raciais, nutrindo um entusiasmo que ao final não escapa, porém, a um percalço: o desvio de foco na liderança do movimento, fato este que alavanca um desdobramento de tensões sociais no Harlem. 
Não obstante, apesar de desiludido pela confraria, o protagonista permanece impactado pela sua experiência, não fazendo concessões ao movimento rival, mobilizado em defesa do separatismo negro.

$\mathrm{O}$ referido movimento separatista ficcional apresenta como líder, por sua vez, um personagem chamado Rás, que encontra paralelos em líderes históricos norte-americanos como Louis Farrakhan, representante do nacionalismo negro. A proposta defendida por Farrakhan era que os negros se vissem como uma nação separada, progredindo separadamente, uma vez que ele temia ver aqueles mais bem-sucedidos distanciados de suas comunidades, portanto "assimilados" ao universo dos brancos. Nesse sentido, ele destacava o poder de afirmação da comunidade negra diante dos brancos, apresentando, conforme a avaliação de Magnoli (2009, p.128), uma perspectiva regida pelas noções de "raça" como fonte primordial de identidade e de separação entre as nações "branca" e "negra" como única solução efetiva para o impasse do racismo. No entanto, Magnoli conclui sua discussão com a ressalva de que, a partir do momento em que uma raça obtém sentido em contraste com outra, as partes tendem a permanecer claramente delimitadas, destinadas, portanto, a não se encontrarem.

No Brasil, por outro lado, conceber a identidade em torno da origem étnica, assim como de valores culturais, traz consigo a problemática de delimitar o espaço de jogo de cada identidade, uma vez que, com a mestiçagem cultural aqui existente, identidades se entrecruzam e se assimilam. Tal cenário de pluralidade tem por alicerce a concepção ideológica de que a afirmação de identidade étnica representa um alijamento da sociedade nacional - motivo pelo qual o Brasil não é marcado, por exemplo, por movimentos separatistas. Essa ideologia desperta "em toda a população, por mais heterogênea que seja, o sentimento de um destino comum, com maior poder de mobilização que o de origem étnica particular" (MUNANGA, 2004, p.135), de modo que há dificuldade em construir uma identidade "pura", isenta de mistura.

De fato, a percepção do relativo abrandamento das tensões raciais em comparação com a sociedade norte-americana, dado o 
estímulo a uma visão integracionista, constitui um elemento central da análise sociológica de Sérgio Milliet em seu Diário Crítico. Milliet (1898-1966), artista de vanguarda e crítico literário brasileiro, faz nessa obra uma avaliação (MILLIET, 1981, p.100) comentada por Amorim (2012, p.122) nos seguintes termos:

\begin{abstract}
No argumento de Milliet, a miscigenação teria produzido no Brasil um espaço de familiaridade e de proximidade entre brancos e negros que teria impossibilitado a emergência de uma consciência de "raça" entre os últimos. Além disso, embora reconheça a existência do preconceito de cor no solo brasileiro, o crítico argumenta que ele seria "um preconceito muito atenuado", que "não mata a planta humana, como na América do Norte", de modo que também "não estrutura minorias conscientes".
\end{abstract}

Embora o preconceito racial brasileiro historicamente tenha se manifestado de maneiras distintas do cenário norte-americano, não contemplando leis segregativas, o movimento afro-brasileiro contemporâneo tem destacado que o estágio final de integração como expressão de uma sociedade unirracial e unicultural poderia se configurar, porém, como um modelo que assimilaria as outras culturas à cultura branca. Desse modo, ao se defrontar com o ideário de branqueamento e a ambiguidade de não ser "nem um, nem outro", o mestiço, especificamente, se situa em um estado de permanente indefinição, uma vez que ele tem dificuldade tanto em estabelecer sua identidade mestiça como em optar por declarar-se negro, ao mesmo tempo em que espera para se tornar "branco". Por conseguinte, atualmente os movimentos afro-brasileiros contemporâneos têm por objetivo redirecionar o foco para a valorização de uma cultura não assumida em virtude do sonho de branqueamento, ação que se dirige também e em particular aos descendentes de negros cujas raízes poderiam passar despercebidas.

Partindo de um contexto de mestiçagem fortemente marcado no imaginário coletivo, o movimento negro tem se empenhado, 
portanto, para formar uma comunidade engajada em favor de sua negritude, à semelhança de grupos afro-americanos.

\section{Invisible Man e sua tradução - perspectivas em torno de senso de comunidade e integração racial}

Conforme assinalado anteriormente, o contexto de negritude nos Estados Unidos apresenta um histórico de tensões acompanhadas de polarização entre grupos raciais. Assim, ante o cenário conflituoso da própria identidade, uma resposta ao entorno social pode ser, em nível de grupo, um senso de comunidade aprofundado. Touré (2011, p.158) explica: "In a community that feels under siege it can seem crucial to keep all your soldiers together and not let people stray and so markers of staying with the herd become very important ${ }^{2}$."

$\mathrm{O}$ modo como essa consciência permeia a comunidade afro-americana vem à tona em passagens do romance de Ellison nas quais determinado posicionamento ou certas construções refletem a identificação promovida entre os membros do grupo. Como exemplo, segue um trecho no qual o personagem principal - narrador anônimo - manifesta unidade entre ele e outros negros independentemente de conhecê-los. Em um diálogo com Jack, presidente branco da confraria inter-racial, o narrador é questionado sobre o fato de haver acabado de proferir um discurso espontâneo em defesa de um casal negro no Harlem que estava no processo de ser despejado da própria habitação:

\footnotetext{
"But you were concerned with that old couple," he said with narrowed eyes. "Are they relatives of yours?" "Sure, we're both black," I said, beginning to laugh.

He smiled, his eyes intense upon my face.

"Seriously, are they your relatives?"

"Sure, we were burned in the same oven," I said.

(ELLISON, 2001, p.292)
} 
- Mas você se interessou por aquele casal de velhos disse ele, apertando os olhos. - Eles são seus parentes?

- Claro, os dois são pretos - respondi, caindo na risada.

- Falando sério: são seus parentes?

- Claro: fomos torrados no mesmo forno.

(ELLISON, 1990, p.251)

A resposta do protagonista assume um tom jocoso, inclusive explicitado por risos, ante a consciência do mesmo de quebrar a expectativa de Jack sobre o conceito de "parentesco" como relação familiar direta. Trata-se de identificação plena com o discurso de coesão da comunidade afro-americana, uma maneira de pensar, porém, estranha a Jack, de modo que suscita neste a reação irritada "Por que é que vocês sempre falam em termos de raça?" (ELLISON, 1990, p.251). Nesse sentido, poder-se-ia dizer que a opção de traduzir "we are both black" por "os dois são pretos" se dá como que em sutil reação à pergunta de Jack: o narrador não se autoafirma negro, mitigando a expressão do seu vínculo racial com o casal de negros ao deixá-lo apenas implícito.

Resulta significativo, conforme observado no exemplo anterior, que o senso de comunidade se materialize linguisticamente no emprego de pronomes específicos em contextos marcados pela expressão de pertencimento racial. Tais contextos vêm a ressaltar nuances de sentido inerentes a paráfrases, direcionando, assim, a leitura dos pronomes como formas de o falante considerar-se explícita ou apenas implicitamente membro de uma coletividade. Essa diferença entre as possibilidades de marcação do senso de grupo manifesta-se também na tradução de uma fala do narrador na qual ele precisa decidir com qual estratégia se dirigir ao público, descrevendo a sua abordagem nos seguintes termos:

I had to fall back upon tradition and since it was a political meeting, I selected one of the techniques that I'd heard so often at home: The old down-to-earth, I'm-sick-and-tired- 
of-the-way-they've-been-treating-us approach.

(ELLISON, 2001, p.342, grifo nosso)

No trecho em inglês, o narrador expõe sua estratégia em termos de um sentimento inerente tanto a ele quanto àqueles endereçados como seus pares, ao passo que em português, ele fala por si:

Tive que recorrer à tradição; e, como aquilo era uma reunião política, escolhi uma das técnicas políticas que tantas vezes testemunhara em casa: a abordagem pé-no-chão, tipo "tô-cheio-de-ser-tratado-desse-jeito".

(ELLISON, 1990, p.293)

Em contraste com o pressuposto de coletividade presente no original, a tradução funciona, portanto, nos moldes de um implícito, delegando ao leitor o movimento de derivar uma dimensão coletiva da experiência pessoal do narrador.

Transportar uma experiência do plano pessoal para o coletivo constitui, com efeito, um mecanismo para a expressão de um sentimento de grupo. Em outro contexto, por sinal, o narrador em inglês efetua o mesmo movimento, empregando uma afirmação sobre si mesmo para caracterizar outros afro-americanos. Não obstante, as frases do trecho em questão são elencadas de tal modo que se obtém uma relação direta, inerente à compreensão do texto, mediante uma conexão lógica que cria uma relação de escopo da dimensão individual sobre a coletiva:

These fellows whose bodies seemed - what had one of my teachers said of me? - "You're like one of these African sculptures, distorted in the interest of a design".

(ELLISON, 2001, p.440) 
Na tradução, em contrapartida, o alcance da afirmação do professor sobre negros se estende aos afrodescendentes, porém não de modo a incluir o próprio narrador:

\begin{abstract}
Aqueles rapazes, cujos corpos pareciam... (como se expressara mesmo aquele professor? "Vocês parecem essas esculturas africanas, deformadas em função de um projeto"...) (ELLISON, 1990, p.376-377)
\end{abstract}

A noção de coletividade é construída neste trecho explorando-se o tratamento no plural como uma das possibilidades de interpretação do pronome "you", mas diluindo-se, por conseguinte, a implicação pessoal do protagonista no comentário do professor.

Em resumo, os exemplos precedentes deram ensejo a uma discussão sobre princípios do senso de comunidade expressos pela referenciação pronominal. Para além disso, porém, as formas de expressão de tal sentimento estendem-se também ao modo de identificação de aspecto físico.

$\mathrm{Na}$ sua forma mais marcada, a preocupação em nutrir um senso de comunidade pode converter-se em aguçada sensibilidade àqueles externos ao grupo, conforme ilustra Invisible Man ao narrar o temor da confraria do protagonista diante da reação do movimento separatista negro àqueles de pele branca. A passagem a seguir expressa a preocupação de uma mulher da confraria ante o líder separatista Rás, também chamado de Exortador, e seus seguidores. Nota-se que os excertos em inglês e em português expressam tal temor sob duas perspectivas distintas, de sorte que, em inglês, a comparação com um frango frito se destina a mostrar como o fato de se ter pele branca salta à vista dos seguidores, incitando-os à violência:

\footnotetext{
"We'll have trouble with the Extortor - I mean the Exhorter," a big woman said. "His hoodlums would attack and denounce the white meat of a roasted chicken."

(ELLISON, 2001, p.365)
} 
Em português, por outro lado, enfoca-se como os mesmos se mostram impiedosos no trato com aqueles de pele branca:

- Vamos ter problemas com o Entortador, isto é, o Exortador - disse uma mulher grandalhona. - Os asseclas dele são capazes de atacar e fritar carne branca como quem frita um franguinho na frigideira. (ELLISON, 1990, p.313)

Como o texto em inglês destaca as implicações do traço "pele clara" para os separatistas mediante a comparação entre a cor do frango e pessoas brancas, percebe-se que o conflito inter-racial aparece arraigado na hipersensibilidade de Rás e os demais extremistas com relação ao aspecto físico. No texto traduzido, por outro lado, está em foco o ato de atacar aqueles de pele branca, lendo-se na imagem de "atacar (...) como quem frita um franguinho na frigideira" principalmente uma manifestação do potencial de violência. Em suma, a tradução se volta para a expressão de animosidade por ações, enquanto o original expõe como essa animosidade está plasmada, antes de tudo, na mentalidade com a qual o Outro branco é absorvido, de modo que as percepções do racismo pela tradutora e por Ellison enfatizam, respectivamente, a externalização do preconceito e a inerência da leitura racializada do Outro.

A sensibilidade à cor de pele é retratada igualmente a partir da marcação de uma dicotomia preto/branco na percepção de outros personagens pelo narrador. Observe-se abaixo como, em determinadas passagens, ele assinala a negritude do rosto de um personagem chamado Trueblood:

"You did and are unharmed!" he shouted, his blue eyes blazing into the black face with something like envy and indignation. (ELLISON, 2001, p.51) 
— Você fez isso e saiu incólume! — gritou Norton, os olhos azuis desferindo chamas no rosto escurecido, com um misto de inveja e indignação. (ELLISON, 1990, p.49)

Nesse trecho, a narrativa do contato entre um branco - Sr. Norton, um dos mantenedores da universidade do narrador - e um negro é sublinhada pelo contraste entre os olhos claros de um e a pele escura de outro. Enquanto a palavra "black", porém, quando em contexto descritivo - isento da dimensão ideológica de negritude - , marca uma cor de pele notadamente escura, a tradução apresenta a cor do rosto de Trueblood dentro de uma nuance que varia conforme a referência tomada pelo leitor. Ou seja, na tradução por "rosto escurecido", há um espectro ampliado de interpretações em comparação com o adjetivo "preto", similar a "black" como polo de uma relação antonímica entre "preto"/"branco", fato este que remete à "escala cromática de valores" na qual a negritude se desdobra no Brasil, conforme discussão de Aurora Neiva (1997, p.533). Essa conclusão dialoga com outras passagens, como a descrição a seguir, que elide a menção à cor de pele de Trueblood. Tem-se como única referência anterior no texto precisamente a caracterização feita acima, de modo que se somam indícios para a fuga, na tradução, de descrições em termos dicotômicos:

With his bright eyes burning into Trueblood's black face, he looked ghostly. (ELLISON, 2001, p.68)

Parecia um fantasma, os olhos ardentes penetrando como brasas no rosto de Trueblood. (ELLISON, 1990, p.63)

Em paralelo com a omissão da cor de pele na segunda menção a Trueblood, também se observa ausência de adjetivo na passagem a seguir. $\mathrm{O}$ narrador, recém contratado em uma empresa de tintas, é informado pelo seu supervisor de mistura de cores sobre as circunstâncias de sua contratação: 
"Oh, you know. The wise guys firing the regular guys and putting on you colored college boys. Pretty smart," he said. "That way they don't have to pay union wages." (ELLISON, 2001, p.197)

- Ora, não vai me dizer que não sabe! Isso dos maiorais botarem na rua os operários antigos e contratarem universitários que nem você. Até que eles são vivos - acrescentou. - Desse jeito, não precisam pagar os salários estabelecidos pelo sindicato... (ELLISON, 1990, p.169)

O conjunto de exemplos relacionados à menção de cor de pele indica que o pertencimento a determinado grupo racial pode ser reiterado e reforçado. No exemplo em questão, reforça-se a relação implicativa entre "cor" e "posição social": em si, seria o fato de os estudantes ainda não estarem oficialmente no mercado de trabalho, e, portanto, sob as leis trabalhistas, a causa primeira da contratação dos mesmos; no entanto, o comentário do supervisor está acompanhado de uma observação sobre cor de pele que funciona como uma avaliação empírica sobre o perfil dos contratados, dando a entender que os brancos não são candidatos à mesma função que os negros. Na tradução, por outro lado, a construção "que nem você", correspondente a "colored", recupera a condição de "estudante", colocando em segundo plano a cor de pele e, com isso, a possibilidade de que a mesma tenha alguma relação com o tipo de trabalho exercido.

Em se tratando de implicações sociais de raça, a narrativa igualmente aborda o aspecto de segregação, aludindo à mesma na forma de uma conversa sobre a divisão de assentos ouvida pelo narrador no ônibus:

"Aw, quit trying to show off your education," Crenshaw said. "You riding back here in the Jim Crow just like me." (ELLISON, 2001, p.155) 
- Ora, pára de ficar exibindo a tua instrução - protestou Crenshaw. - Tu tá viajando aqui atrás, na rabeira, que nem eu. (ELLISON, 1990, p.135)

O epíteto Jim Crow constitui uma alcunha dada aos negros e estendida às leis segregacionistas, legislação cuja falta de correspondência no contexto brasileiro é refletida na escolha por "na rabeira", uma expressão indicadora de localização espacial, mas de todo modo associada à ideia de preterição. Possivelmente pelo fato de os personagens negros na cena demonstrarem a obrigação de sentar em lugares delimitados, também não houve, por outro lado, maior preocupação em explicitar a segregação racial com algum adendo que traga à baila a questão de "ser negro". Desse modo, pode-se dizer que a tradutora não se mostra incisiva no aspecto racial, antes apoiando sua opção tradutória no esclarecimento provido pelo contexto.

Como conclusão para os diferentes pontos de conflito abordados ao longo do livro, Ellison promove, então, no epílogo, uma reflexão sobre o rumo a ser tomado nas relações inter-raciais, colocando em pauta novamente o discurso de integração da confraria multirracial. Apesar de haverem ocorrido falhas na condução da confraria, o narrador não renuncia, portanto, ao princípio de integração racial, considerando necessária, porém, uma aproximação que passe pelo reconhecimento do valor de negritude:

Thus one of the greatest jokes in the world is the spectacle of the whites busy escaping blackness and becoming blacker every day, and blacks striving toward whiteness, becoming quite dull and gray. (ELLISON, 2001, p.577, grifos nossos

Por isso, uma das coisas mais ridículas do mundo é ver os brancos fingindo que são negros e se fazendo mais negros a cada dia que passa, enquanto os negros lutam para ser brancos e vão ficando dia a dia mais cinzentos e mais sem graça. (ELLISON, 1990, p.495, grifos meus) 
Primeiramente, mostra-se propício analisar na tradução o tom conferido à proposta revisionista do narrador, sendo perceptível uma diferença no modo como é absorvida a avaliação sobre as relações contraditórias de brancos e negros com negritude. Para isso, note-se a existência de um recorte interpretativo no qual o "espetáculo" ("spectacle") que constitui uma "grande piada" ("great joke") é sintetizado na tradução por "uma das coisas mais ridículas". Em vista do emprego de "ridículo", essa construção assume um marcado viés negativo, ao passo que o trecho em inglês se caracteriza por certa ambivalência, ante a possibilidade de uma leitura em princípio mais analítica e menos valorativa na qual se tomem os esforços de uns e de outros como uma atitude que de um lado chama atenção, como um espetáculo, e, de outro, incorre em uma quebra de expectativa, à semelhança de uma piada. Por conseguinte, o narrador em inglês descreve o insucesso dos respectivos empenhos por meio de uma ironia cujo "não dito" a crítica manifestada na tradução se propõe a explicitar.

Assim como a ironia descrita acima recebe ênfase em uma de suas possibilidades de interpretação, também o paradoxo no tocante à relação dos brancos com a negritude é desfeito na leitura da tradutora, recebendo um tom crítico. Em inglês, a passagem acima desperta a noção de que a negritude se inscreve em uma dinâmica de intercâmbio sociocultural, permeando, assim, a sociedade de uma forma alheia a qualquer tentativa de escape - concepção, por sinal, alinhada com o engajamento de Ellison a favor da ideia de que "os Estados Unidos sempre tiveram uma cultura racialmente mista e que ninguém pode crescer no país sendo inteiramente 'branco' ou 'negro'" (MENAND, 1999, p.6). Na tradução, por outro lado, os brancos fazem um esforço artificial para se tornarem negros, o que representaria uma crítica condizente com a mentalidade cética de Rás. O líder separatista rejeita o contato com brancos temeroso de que a aproximação dos mesmos não reflita interesse genuíno pela negritude, mas antes acabe por influenciar os negros no sentido do embranquecimento cultural. A consequente perda identitária seria retratada, por sua vez, na sequência do raciocínio do personagem 
no epílogo, conforme o qual os negros se tornam cinzentos e sem graça ao lutarem para serem brancos. Desse modo, a partir da diferença apresentada pela tradução no tocante à relação entre os brancos e a negritude, a tradutora fecha um círculo lógico condizente com a perspectiva do separatismo negro, fornecendo um indício para a percepção brasileira de nítida delimitação, no contexto norte-americano, entre grupos raciais. A construção do Outro pela tradutora se daria, assim, de acordo com uma expectativa que o leitor brasileiro desenvolve sobre a sociedade norte-americana a partir da sua autopercepção, ou seja, em contraste à narrativa de um povo brasileiro não polarizado em termos raciais.

Considerando esse panorama, Munanga (2004, p.135) percebe os brancos como de fato mais "africanizados" e os negros mais "ocidentalizados" do que imaginam, por sinal convergindo para a visão do personagem de Ellison. Em sua linha argumentativa, ele avalia, porém, que a virtual impossibilidade de circunscrição da negritude ante o histórico brasileiro de miscigenação constitui um desafio ao movimento negro, que, frente a isso, conclama à valorização da identidade negra não apenas negros fenotípicos, mas principalmente afrodescendentes que não aparentam sê-lo, ou seja, aqueles que passam por "brancos".

Em resumo, o apelo à descoberta de negritude para além de aparentes fronteiras raciais, perspectiva ilustrada pela discussão de Munanga e advogada por Ellison, confronta a possível expectativa da tradutora com relação ao panorama de racialidade nos Estados Unidos. Por conseguinte, o epílogo, como espaço de conclusão, parece despertar na tradutora a busca por conferir ao desfecho coerência discursiva, embasada, no contexto literário, pelo fracasso da proposta integracionista à qual o narrador aderira e, no contexto social, pela dicotomia percebida como inerente às relações raciais norte-americanas. 


\section{Considerações finais}

Ao longo da discussão, buscou-se pontuar especificidades tradutórias passíveis de diálogo com a questão de negritude, notando-se como particularidades tanto a flexibilidade na referenciação de aspectos relativos à mesma quanto a asseveração conclusiva de dicotomia racial. Como desfecho, sugerimos, nesse sentido, algumas hipóteses interpretativas.

A apropriação menos incisiva do atributo "black", como "sema" relacionado a ser negro, possivelmente representa uma fuga da repetição de palavras. De modo semelhante, a mitigação do senso de comunidade mediante a reformulação de passagens nas quais foram empregados pronomes aqui considerados estratégicos aponta para o preceito estilístico de evitar, na tradução, a sobrecarga de pronomes pessoais passível de ser desencadeada pela estrutura sintática do inglês. Desse modo, parâmetros estéticos se sobrepõem à importância de externar pertencimento, explicitada na medida em que a vivência social se inscreve no uso da linguagem pelos afro-americanos. Por conseguinte, as opções da tradutora, como representante do contexto brasileiro, indicariam uma consciência racial comparativamente menos aguçada, sendo este, então, o motivo pelo qual não se ressaltariam marcas de coletividade e pertencimento.

Observa-se, no entanto, que a relação de destaque a marcas de dicotomia racial se inverte na tradução da passagem do epílogo discutida acima, em virtude do possível estranhamento frente ao cenário integracionista vislumbrado pelo narrador. Com efeito, tal quebra de expectativa registrada na formulação da tradutora mostra-se alinhada com o discurso afrodescendente ao sugerir uma ênfase em racialidade como resposta à falha do modelo de integração. Por conseguinte, de fato, o raciocínio do narrador se esclarece plenamente apenas à medida que se compreenda a referência ao integracionismo na visão ellisonesca e na realidade descrita por Munanga (2004) como releitura da respectiva situação corrente. Em outras palavras, ambos abordam a negritude sob um cenário 
integracionista, Ellison fazendo-o, porém, de forma prospectiva, como Munanga o faz de maneira retrospectiva. Portanto, Munanga reporta-se à integração com vistas à revisão da narrativa de mestiçagem existente, ao passo que Ellison o faz de modo a apresentar uma proposta de aproximação em um contexto de dicotomização.

Ao assumir a referida perspectiva - tanto em Invisible Man como no conjunto da sua produção teórico-literária -, Ellison efetivamente concebeu a identidade afro-americana dentro de moldes distintos daqueles propagados pelo ascendente Poder Negro, concepções estas que vieram a nortear, em boa medida, a percepção do Outro afro-americano pelo leitor brasileiro. Ao descrever os EUA como fundados em um intercâmbio cultural entre brancos e negros ainda não devidamente reconhecido, ele confrontava a visão predominante sobre o rumo a ser tomado pela comunidade americana, de acordo com a qual o florescimento da cultura negra dependia de autonomia com relação a valores da sociedade norte-americana, ou seja, de separação como defesa contra assimilação.

Em suma, ao mesmo tempo em que Invisible Man não deixa, em si, de apresentar uma racialidade subjacente à leitura do mundo, a obra promove a busca por diluir diferenças raciais. De certo modo, a trajetória do romance se desenrola, assim, na contramão da realidade brasileira em relação à negritude, fato que parece incitar a tradutora, por mecanismos tradutórios (in)conscientes, a tornar o panorama da narrativa inteligível a um leitor brasileiro dotado de pressupostos inversos aos de Ellison, embasados no rumo de propalada integração tal como historicamente trilhado pela sociedade brasileira e na resposta da negritude contemporânea. 


\section{Notas}

1. Artigo derivado de pesquisa desenvolvida com apoio da FAPESP (processo 2012/03387-0), sob a orientação do Prof. Dr. Lauro Maia Amorim.

2. Em uma comunidade que se percebe cercada, pode parecer essencial manter todos os soldados reunidos e não deixar as pessoas se desviarem, e assim, marcas de pertencimento à multidão adquirem grande importância (tradução de nossa autoria).

\section{Referências}

AMORIM, L. O papel da tradução na construção da identidade da literatura afro-americana no Brasil. Revista do GEL, São Paulo, v.9, n.1, p.107-134, 2012.

ELLISON, R. Homem Invisível. Trad. Márcia Serra. São Paulo: Marco Zero, 1990.

ELLISON, R. Invisible Man. London: Penguin Books. 2001.

HATTNHER, A. Presença de autores afro-americanos no Brasil: as traduções. Crop, vol. 4, n.5, p. 297-313, 1997-1998.

MAGNOLI, D. Gota de sangue: história do pensamento racial. São Paulo: Contexto, 2009.

MENAND, L. Trad. Clara Allain. Obra ‘Frankenstein' de Ellison sai nos EUA.

Folha de São Paulo, São Paulo, 17 jul. 1999. Ilustrada, p.6. 
MILLIET, S. Diário crítico I (1940-1943)- vol. I. 2. ed. São Paulo: MartinsEdusp, 1981.

MUNANGA, K. Rediscutindo a mestiçagem no Brasil: identidade nacional versus identidade negra. São Paulo: Autêntica, 2004.

NEIVA, A. A relação entre cor e identidade étnica em traduções brasileiras de um romance norte-americano. Estudos Neolatinos 2, Rio de Janeiro, ano 2, n.2, p.531-538, 1997.

SALGUEIRO, M. A mediação de culturas nas traduções de obras de escritoras de origem afro. In: CAVALCANTI, I; LIMA, A; SCHNEIDER, L. (Org.). Da mulher às mulheres: dialogando sobre literatura, gênero e identidades. Maceió: EDUFAL, 2006. p.167-175.

TOURÉ. Who's Afraid of Post-Blackness?: What It Means to Be Black Now. Nova York: Simon and Schuster, 2011.

VENUTI, L. Escândalos da Tradução: por uma ética da diferença. Trad. Laureando Pelegrin et al. Bauru: EDUSC, 2002.

Recebido: 17-01-14

Aceito: 15-03-14 